2. A survey of breeding systems in the genus Plantago has established that there are several species which are both self-incompatible and gynodioecious.

Acknowledgments.--Most of this work was carried out in the Oxford Botany Department and is contained in a D.Phil. thesis submitted to the University of Oxford. I wish to thank Dr L. K. Crowe for supervising the work. I also wish to thank Mr J. K. Burras and $\mathrm{Dr}$ Beal Hyde for supplying seeds. The work was supported by funds from the Department of Scientific and Industrial Research.

\title{
6. References
}

BAKER, H. G. 1963. Evolutionary mechanisms in pollination biology. Science, 139, 877-883. CHANDler, c. 1954. Improvement of Plantago for mucilage production and growth in the United States. Contrib. Boyce Thompson Inst., 17, 495-505.

DARwin, c. 1889. The Different Forms of Flowers on Plants of the Same Species. D. Appleton and Company, New York.

FERNALD, M. L. 1950. Gray's Manual of Botany, 8th ed. American Book Company, New York.

FRösT, s. 1959. The cytological behaviour and mode of transmission of accessory chromosomes in Plantago serraria. Hereditas, 45, 191-210.

Gregor, J. w. 1939. Experimental taxonomy. IV. Population differentiation in North Amierican and European sea plantains allied to Plantago maritima L. New Phytol., 38 , 293-322.

GREGOR, J. W., AND LANG, J. M. s. 1950. Intra-colonial variation in plant size and habit in sea plantains. New Phytol., 49, 135-141.

kNuTh, P. 1909. Handbook of Flower Pollination, Vol. III. Clarendon Press, Oxford.

MATHER, к. 1940. Outbreeding and separation of the sexes. Nature, 145, 484-486.

PAliwal, R. P., AND HYDE, B. B. 1959. The association of a single B-chromosome with male sterility in Plantago coronopus. Amer. 7. Bot., 46, 460-466.

PIlger, R. in Engler, A. 1937. Das Pflanzenreich. IV. 269. Plantaginaceae. Leipzig.

RAHN, K. 1957. Chromosome numbers in Plantago. Dansk Bot. Tidsskr., 53, 369-378.

Ross, M. D. 1969. Digenic inheritance of male sterility in Plantago lanceolata. Can. F. Genet. Cytol., 11, 739-744.

\section{A TEST FOR "AFFINITY" IN MAIZE}

\author{
KENNETH E. MICHEL \\ Department of Biology, Slippery Rock State College, Pennsylvania, U.S.A.
}

Received 28.viii.69

\section{INTRODUCtion}

THE non-random assortment of non-homologous chromosomes has been demonstrated in the "normal" diploid house mouse. Michie (1953, 1955) and Wallace (1953) have offered the hypothesis of affinity to account for the loose genetic association of unlinked genetic markers in this organism. The hypothesis states that at the first meiotic division in hybrids there is a tendency for non-homologous centromeres of the same ancestral origin to segregate to the same pole of the cell. The hypothesis is expanded by Michie (1955) into the possibilities of polar affinity, the centromeres being acted upon independently by some polar force, and mutual affinity, an attraction for each other of centromeres of like origin. The point to be made here is that the centromere is either the controlling force or the structure acted upon. In either case, centromere markers on independent chromosomes would give 
the appearance of being linked. Not only can they appear linked, but affinity makes it possible to obtain recombination values in excess of 50 per cent. (Wallace, 1958).

Lindegren and Shult (1956) have obtained similar results in Saccharomyces and have postulated the theory of ortho-orientation to explain the nonrandom distribution of double recombinants (Shult and Lindegren, 1957). Wallace $(1960 a, b)$ has attempted an affinity interpretation of results obtained in cotton and tomato. Whalen (1965) and Whalen and Johnson (1965) were not able to distinguish whether quasi-linkage demonstrated in tomato was due to non-random assortment or to selective elimination. The present study is undertaken as an attempt to demonstrate the presence of affinity in maize.

\section{Materials AND Methods}

The inbred multiple marker stock (one marker per chromosome and listed in order for chromosomes 1 to 10$) b m_{2}$ (brown midrib), $g_{1}$ (liguleless), $a_{1}$ (lack of anthocyanin), $s u_{1}$ (sugary endosperm), $p r$ (red aleurone), $y_{1}$ (white endosperm), $g l_{1}$ (glossy seedling leaves), $j_{1}$ (white striped plant), $w x$ (waxy endosperm), and $g_{1}$ (golden plant) obtained from the Maize Genetics Cooperation was crossed to three different inbred lines. These inbred lines consisted of W23, developed at Wisconsin; A188, developed at Minnesota; and a non-sugary version of P39A, a sweet corn developed at Purdue. This latter inbred was produced by C. R. Burnham by outcrossing P39A to a non-sugary stock, then selecting for non-sugary during a series of backcrosses to the P39A sugary inbred; followed by selfing and selection of the non-sugary homozygote. The $\mathrm{F}_{1}$ plants were back-crossed as females to the multiple marker and the progeny scored for segregation of $s u, y, g l$, and $w x$. These are centromere markers on chromosomes 4,6,7, and 9 respectively and are located approximately 9 units, 5 units, 9 units, and 4 units from their respective centromeres (Anderson and Randolph, 1945; Hayes, Immer and Smith, 1955).

A population size sufficient to detect a difference between 45 per cent. recombination and random assortment of centromeres at the 0.05 level of significance was determined by the standard error method (Mather, 1939). Since the markers are not completely linked to their centromeres, crossingover between the markers and their centromeres makes it necessary to test for a marker recombination value higher than 45 per cent. Thus, when comparing parental versus non-parental combinations of the two markers most distant from their centromeres, i.e., su and $g l$, a population large enough to detect a difference between $46 \cdot 6$ per cent. recombination and random assortment is needed. When comparing parental versus non-parental combinations of the two markers closest to their centromeres, i.e., $y$ and $w x$, a population size is needed that will detect a difference between 45.9 per cent. recombination and random assortment. The other combinations of markers fall between these two values. The population sizes needed to detect affinity between these chromosomes in these crosses range from 2278 to 3316 . All of the populations in this series of crosses are 3393, or larger in size.

\section{Results}

No affinity was detected in the present study. In the absence of affinity the back-cross progeny would be expected to segregate for the genetic 
markers in a $1: 1$ ratio. This is the result obtained when the markers are taken two at a time and classified for parental and non-parental combinations. The totals for the crosses involving W23, A188, and P39A are given in table 1 .

TABLE 1

Back-cross segregations for various combinations of 2 pairs of independent genes from crosses involving W23, A188, and P39A $\times$ Multiple Marker

\begin{tabular}{|c|c|c|c|c|c|c|c|c|}
\hline \multirow{3}{*}{$\begin{array}{c}\text { Cross and } \\
\mathrm{F}_{1} \text { genotype }\end{array}$} & & & & & & \multicolumn{3}{|c|}{ Parental : Non-parental } \\
\hline & \multicolumn{5}{|c|}{ Segregations } & \multicolumn{2}{|c|}{ Observed } & \multirow{2}{*}{$\begin{array}{l}\text { Calculated } \\
\text { per cent. } \\
\text { needed for } \\
\text { affinity }\end{array}$} \\
\hline & $A B$ & $A b$ & $a B$ & $a b$ & Total & Number & Per cent. & \\
\hline \multicolumn{9}{|l|}{ W23 back-cross } \\
\hline $\begin{array}{l}\text { Su su } \Upsilon_{y} \\
\text { Su su } G l g l \\
\text { Su su } W x w x \\
\Upsilon_{y} G l g l \\
Y_{y} W x w x \\
G l g l W x w x\end{array}$ & $\begin{array}{r}1287 \\
1026 \\
1121 \\
865 \\
952 \\
817\end{array}$ & $\begin{array}{r}1298 \\
1018 \\
1202 \\
815 \\
1026 \\
908\end{array}$ & $\begin{array}{r}1179 \\
720 \\
789 \\
881 \\
958 \\
784\end{array}$ & $\begin{array}{r}1296 \\
667 \\
935 \\
870 \\
1111 \\
884\end{array}$ & $\begin{array}{l}5060 \\
3431 \\
4047 \\
3431 \\
4047 \\
3393\end{array}$ & $\begin{array}{l}2583: 2477 \\
1693: 1738 \\
2056: 1991 \\
1735: 1696 \\
2063: 1984 \\
1701: 1692\end{array}$ & $\begin{array}{l}51 \cdot 0: 49 \cdot 0 \\
49 \cdot 3: 50 \cdot 7 \\
50 \cdot 8: 49 \cdot 2 \\
50 \cdot 6: 49 \cdot 4 \\
51 \cdot 0: 49 \cdot 0 \\
50 \cdot 1: 49 \cdot 9\end{array}$ & $\begin{array}{l}53 \cdot 7: 46 \cdot 3 \\
53.4: 46 \cdot 6 \\
53 \cdot 8: 46 \cdot 2 \\
53 \cdot 7: 46 \cdot 3 \\
54 \cdot 1: 45 \cdot 9 \\
53 \cdot 8: 46.2\end{array}$ \\
\hline \multicolumn{9}{|l|}{ A188 back-cross } \\
\hline $\begin{array}{l}\text { Su su } G l g l \\
\text { Su su Wx wx } \\
G l g l W x w x\end{array}$ & $\begin{array}{r}1006 \\
1108 \\
857\end{array}$ & $\begin{array}{r}996 \\
1212 \\
891\end{array}$ & $\begin{array}{l}749 \\
893 \\
838\end{array}$ & $\begin{array}{l}765 \\
953 \\
910\end{array}$ & $\begin{array}{l}3516 \\
4166 \\
3496\end{array}$ & $\begin{array}{l}1771: 1745 \\
2061: 2105 \\
1767: 1729\end{array}$ & $\begin{array}{l}50 \cdot 4: 49 \cdot 6 \\
49 \cdot 5: 50 \cdot 5 \\
50 \cdot 5: 49 \cdot 5\end{array}$ & $\begin{array}{l}53 \cdot 4: 46 \cdot 6 \\
53 \cdot 8: 46 \cdot 2 \\
53 \cdot 8: 46 \cdot 2\end{array}$ \\
\hline \multicolumn{9}{|l|}{ P39A back-cross } \\
\hline $\begin{array}{l}\text { Su su } \Upsilon_{y} \\
\text { Su su } G l g l \\
\text { Su su } W x w x \\
\Upsilon_{y} G l g l \\
Y_{y} W x w x \\
G l g l W x w x\end{array}$ & $\begin{array}{r}1261 \\
1008 \\
1131 \\
978 \\
1048 \\
928\end{array}$ & $\begin{array}{r}1182 \\
931 \\
1155 \\
903 \\
1049 \\
908\end{array}$ & $\begin{array}{r}1167 \\
831 \\
882 \\
861 \\
965 \\
841\end{array}$ & $\begin{array}{r}1163 \\
825 \\
910 \\
853 \\
1016 \\
898\end{array}$ & $\begin{array}{l}4773 \\
3595 \\
4078 \\
3595 \\
4078 \\
3575\end{array}$ & $\begin{array}{l}2424: 2349 \\
1833: 1762 \\
2041: 2037 \\
1831: 1764 \\
2064: 2014 \\
1826: 1749\end{array}$ & $\begin{array}{l}50 \cdot 8: 49 \cdot 2 \\
51 \cdot 0: 49 \cdot 0 \\
50 \cdot 0: 50 \cdot 0 \\
50 \cdot 9: 49 \cdot 1 \\
50 \cdot 6: 49 \cdot 4 \\
51 \cdot 1: 48.9\end{array}$ & $\begin{array}{l}53 \cdot 7: 46.3 \\
53.4: 46.6 \\
53 \cdot 8: 46 \cdot 2 \\
53 \cdot 7: 46 \cdot 3 \\
54 \cdot 1: 45 \cdot 9 \\
53.8: 46.2\end{array}$ \\
\hline
\end{tabular}

Under " segregations ", $A$ stands for the mutant placed first in the $\mathrm{F}_{1}$ genotype, $B$ for the next, e.g. for Su su $Y_{y, A}=S u, B=Y$.

The sugary character has the effect of reducing germination and thus there are more non-sugary progeny. However, the effect of sugary is the same on both the parental and the non-parental combinations and therefore a $1: 1$ ratio should still be expected. Inbred A188 is homozygous for $y$ and therefore segregation results with this cross were obtained for only 3 of the 4 markers.

In every combination of markers in all 3 crosses the segregation of parental and non-parental combinations is not significantly different from the expected $1: 1$ ratio. In fact, in no case does the ratio of parental to nonparental even approach that which might be expected with affinity but rather is consistently close to 50 per cent. of each type. Therefore, it is concluded that affinity is not present in the stocks used or under the conditions of this study. It seems probable that affinity also would not be detected in the other chromosomes in these crosses.

\section{Discussion}

All cases of affinity thus far reported have had a 5 to 10 per cent. deviation from 50 per cent. recombination (Michie, 1955; Wallace, 1959, 1960b). 
Even though this deviation is small, the populations in the present study were sufficiently large to detect a deviation of this magnitude. Since the markers used are known to be sufficiently near their centromeres either (l) the centromeres of the lines used are the same, or (2) there is no affinity in corn.

Wallace (1961) points out that heterocentricity may be expected in the $F_{1}$ of outcrosses but that it is not always present. It is present only when the stocks used in the outcross differ in their centrotype. The four lines used in the present study are of different origin and one might expect that at least one of them would differ in centrotype.

The failure to demonstrate affinity in the present study does not mean that it does not exist in corn. It is possible that in this study the multiple marker stock may be a highly heterogeneous mixture of centrotypes, due to the number of stocks and crosses that had to be made to establish it. There is no evidence of heterogeneity, but the differences would be small and difficult to detect. Further investigation might include other inbred lines with centromere markers on different chromosomes. A more effective approach might be to make crosses between more diverse stocks such as inbred lines and Mexican maize or even interspecific crosses between corn and teosinte.

\section{Summary}

1. An inbred multiple marker stock was crossed to the three different inbred lines W23, A188, and P39A and the $\mathrm{F}_{1}$ 's back-crossed as females to the multiple marker stock.

2. The back-cross progeny were observed for any non-random assortment of chromosomes by following the segregation of four independent centromere markers taken two at a time, i.e., su, $y, g l$, and $w x$.

3. The ratio of parental to non-parental combinations of markers is not significantly different from a $1: 1$ ratio in any of the trials.

4. This random assortment of the markers indicates there is a lack of affinity in the crosses with these inbred lines of corn. This also indicates that in these crosses the particular centromeres involved in this study have no role in non-random assortment.

5. Possible reasons for not detecting affinity in corn are discussed in addition to suggestions for further investigation.

\section{REFERENCES}

ANDERSON, E. G., AND RANDOLPH, L. F. 1945. Location of the centromeres on the linkage maps of maize. Genetics, 30, 518-526.

HAYES, H. K., IMMER, F. R., AND SMTTH, D. c. 1955. Methods of Plant Breeding, 2nd ed. McGrawHill, New York.

LINDEGREN, c. C., AND sHULT, E. E. 1956. Non-random assortment of centromeres with implications regarding random assortment of the chromosomes. Experientia, 12, 177-178. MATHER, x. 1938. The Measurement of Linkage in Heredity. Methuen, London.

MICHIE, D. 1953. Affinity: a new genetic phenomenon in the house mouse. Nature, 171, 26-27.

Michie, D. 1955. "Affinity". Proc. Roy. Soc. London B., 144, 241-258.

SHULT, E. E., AND LINDEGREN, C. C. 1957. Ortho-orientation: a new tool for genetical analysis. Genetica, 29, 58-82.

WALlACE, M. E. 1953. Affinity: a new genetic phenomenon observed in the house mouse. Nature, 171, 27-28.

WAllace, M. E. 1958. Experimental evidence for a new genetic phenomenon. Phil. Trans. Roy. Soc. London B., 241, 211-254. 
WALLACE, M. E. 1959. An experimental test of the hypothesis of affinity. Genetica, 29, 243-255.

WALlACE, M. E. 1960a. Possible cases of affinity in cotton. Heredity, 14, 263-274.

WALLACE, M. E. 1960b. A possible case of affinity in tomatoes. Heredity, 14, 275-283.

WALLACE, M. E. 1961. Affinity: evidence from crossing inbred lines of mice. Heredity, 16, $1-23$.

WHALEN, R. H. 1965. Genetic segregation in some interspecific and intergeneric hybrids of Lycopersicon and Solanum. Ph.D. thesis, Department of Horticulture, Purdue University. WHALEN, R. H., AND JoHNson, K. w. 1965. Segregation in hybrids of Lycopersicon esculentum $\times$ L. hirsutum and L. esculentum $\times$ Solanum pennellii. Tomato Genet. Coop. News Letter, 15, 63-64.

\title{
THE ORIGIN OF A DIPLOID "HYBRID" OF CERCOSPORELLA HERPOTRICHOIDES
}

\author{
J. M. L. DAVIES and D. GARETH JONES \\ Department of Agricultural Botany, University College of Wales, Aberystwyth, Wales
}

Received 2.x.69

VARIATION between different isolates of $C$. herpotrichoides has been reported by various workers with respect to morphology (Sprague and Fellows, 1934; Cunningham, 1965; Lange-de la Camp, 1966), growth in liquid cultures (Macer, 1961), and spore prdouction (Glynne, 1953). We have found comparable differences between wild isolates investigated in this laboratory. The sources of variation are not fully elucidated. The following work establishes that hyphal and nuclear fusion contribute to the origin of new variation.

TABLE 1

$$
\text { The "parental" isolates }
$$

\begin{tabular}{lll} 
& $\mathrm{T}$ & \multicolumn{1}{c}{$\mathrm{B}$} \\
Host & Wheat & Barley \\
Colour & Black & White \\
Growth & Slow & Fast \\
Spore production & High & Low
\end{tabular}

Two isolates (described in table 1) were co-inoculated on petri dishes containing potato dextrose agar and incubated at $23^{\circ} \mathrm{C}$. until their " hyphal fronts" met. Hyphal tips were taken, from the black and white isolates to check their stability, and from the central portion where the two isolates met. These were then grown on water agar for two days in order to facilitate the spread of individual mycelia as on potato dextrose agar the hyphal tips were compacted together and it was virtually impossible to obtain single hyphal tips. These hyphal tips were then transferred by use of a finely drawn glass rod on to petri dishes containing potato dextrose agar. Tips taken from the black and white portions gave rise to black and white colonies. Of the tips taken from the central portion six produced colonies intermediate in colour between black and white. One of these grey isolates $(T / B 4)$ was investigated in detail.

It appeared probable that the grey colony was a heterokaryon. Unfortunately, when subjected to conditions suitable for sporulation (Jones and 